\title{
Synthesis and characterization of polymethylsilsesqui oxane microspheres by the two-step sol-gel method
}

\author{
Jiangbo Wang, ${ }^{1,2}$ Zhong Xin ${ }^{1 *}$ \\ ${ }^{1}$ State-Key Lab of Chemical Engineering, School of Chemical Engineering, East \\ China University of Science and Technology, Shanghai 200237, P. R. China \\ ${ }^{2}$ School of Chemical Engineering, Ningbo University of Technology, Ningbo 315016, \\ P. R. China; tel: +86-021-64252972; fax: +86-021-64240862; e-mail: \\ xzh@ecust.edu.cn
}

(Received: 06 February 2011; published: 08 April, 2012)

\begin{abstract}
Polymethylsilsesquioxane (PMSQ) microspheres with an average diameter of $30 \mathrm{~nm}$ to $6 \mu \mathrm{m}$ were prepared from methyltrimethoxysilane (MTMS) by a two-step sol-gel method in the presence of hexadecyl trimethyl ammonium chloride (HTAC). The reaction conditions including the concentration of HTAC, water/MTMS ratio, $\mathrm{pH}$ value and the temperature in condensation reaction were examined, and aggregation of the microspheres was not observed during the preparation process. Moreover, the structure and thermal stability of PMSQ microspheres were investigated by FT-IR, XRD, TGA, and so on.
\end{abstract}

\section{Introduction}

Representative applications of polymethylsilsesquioxane (PMSQ) microspheres include coating for optical and electrical devices [1,2], additive powders for cosmetics $[3,4]$, plastics [5,6], light-diffusing films [7-9], and so on [10]. There have been several reports on synthesis of PMSQ microspheres by the sol-gel method [11-13]. Two types of sol-gel methods have been used. One is the method that does not use any surfactant, which can prepare the PMSQ microspheres with an average diameter of

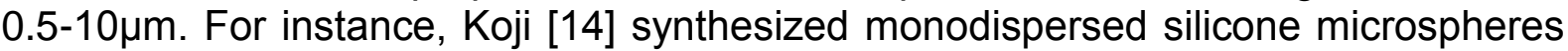
from a basic medium. Yoshinori [15] prepared them by using various organofunctional silicone alkoxides and aqueous ammonia. And the other method for preparing PMSQ microspheres depends on a reaction field of water/oil (W/O) emulsion consisting of a surfactant (or long chain alcohol), an organic solvent, and an aqueous solution [16-18].

In addition, there are two further kinds of methods within the second method previously mentioned that used a reaction field of W/O emulsion [19-24]. For the first kind, silicon alkoxide is added to $\mathrm{W} / \mathrm{O}$ emulsion formed by the surfactant, organic solvent, and aqueous solution [25,26]. For the second, after the hydrolization of silicone in it, the aqueous solution is added to a hydrophobic mixture of a surfactant and an organic solvent. It is reported that the microspheres with an average diameter between 0.3-1.0 $\mathrm{mm}$ have been obtained when adopting a non-ionic emulsifier, and PMSQ microspheres with an average diameter between $0.2-5.0 \mu \mathrm{m}$ are once prepared through an anionic emulsifier [27, 28]. Nevertheless, only few reports are available that investigates the preparation of PMSQ microspheres by the two-step 
sol-gel method in the presence of a cationic surfactant, especially in the sizecontrolled preparation technology of PMSQ microspheres.

Meanwhile, the spherical PMSQ microspheres with an average diameter below $0.5 \mu \mathrm{m}$ are in a large requirement for some certain applications at present, especially in order to improve the properties of polyester films such as lubrication, transparency and flame retardant [29-32]. In this paper, we report a selective method for preparing smaller PMSQ microspheres by two-step sol-gel method in the presence of hexadecyl trimethyl ammonium chloride (HTAC). Spherical PMSQ microspheres with an average diameter from about $30 \mathrm{~nm}$ to $6 \mu \mathrm{m}$ were obtained, of which the thermal stability and structure were also studied.

\section{Results and discussion}

The hydrolysis and condensation reaction of methyltrimethoxysilane was extensively studied. In the first step, the MTMS monomer is hydrolyzed in the presence of water, which produces molecules with hydroxyl groups bonded to $\mathrm{Si}$ atoms. The process can be expressed as following:

$$
\begin{aligned}
& \left.\left.\mathrm{CH}_{3} \mathrm{Si}\left(\mathrm{OCH}_{3}\right)_{3} \underset{-\mathrm{H}^{+}}{\stackrel{+\mathrm{H}^{+}}{\rightleftharpoons}} \mathrm{CH}_{3}\right|_{\mathrm{OCH}_{3}} \mathrm{HiCH}_{3}\right)_{2} \frac{\begin{array}{c}
+\mathrm{H}_{2} \mathrm{O} \\
\text { (slow step) }
\end{array}}{-\mathrm{CH}_{3} \mathrm{OH}} \\
& \underset{\mathrm{OH}}{\mathrm{CH}_{3} \mathrm{Si}\left(\mathrm{OCH}_{3}\right)_{2}+\mathrm{H}^{+} \stackrel{\text { subsequent hydrolysis steps }}{\longrightarrow} \mathrm{CH}_{3} \mathrm{Si}(\mathrm{OH})_{3}}
\end{aligned}
$$

Then, a second condensation reaction was used to form the PMSQ microspheres and the condensation mechanism of these silanol groups was confirmed by:

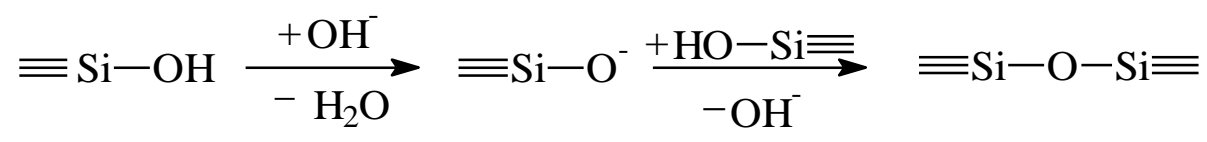

Therefore, the general summation of condensation reaction can be described as following:

$$
\mathrm{nCH}_{3} \mathrm{Si}(\mathrm{OH})_{3} \stackrel{\mathrm{OH}^{-}}{\longrightarrow}\left(\mathrm{CH}_{3} \mathrm{SiO}_{1 \cdot 5}\right)_{\mathrm{n}}+1.5 \mathrm{n} \mathrm{H}_{2} \mathrm{O}
$$

A typical cationic surfactant HTAC was added in the condensation process in this paper. The cationic surfactant has the capability of influencing the interfacial tension between the microsphere and solution. Nevertheless, the synthesis of the PMSQ microspheres generated by the sol-gel process using silane alkoxides is also very dependent on other reaction conditions, i.e. $\mathrm{pH}$, reaction time, temperature, stirring speed and the water/monomer ratio.

\section{Effect of concentration of HTAC on the size and morphology of PMSQ microspheres}

The preparation of PMSQ was investigated when employing a cationic surfactant. Table1 shows the relationship between the concentration of HTAC and the size of PMSQ microspheres prepared in the case of MTMS. The average diameter of the PMSQ microspheres is in the range from 0.03 to $6.0 \mu \mathrm{m}$ when the concentration of HTAC is kept in a certain scale covering the critical micelle concentration (CMC) 
which is around $1.4 \mathrm{mmol} / \mathrm{L}$. It is found that the more amount of HTAC is used, the smaller PMSQ microspheres are formed, which varies from the situation when nonionic or anionic surfactant is used [27]. In other words, the smallest PMSQ microspheres are formed around the CMC of each emulsifier under the last two circumstances. The standard deviation of the microsphere size diameter is considered as an important factor for evaluating PMSQ microspheres prepared in large scale. It can be seen that the standard deviation of $P M S Q$ microsphere decreases with an increase of the emulsifier.

Tab. 1. Effect of concentration of HTAC on the size of PMSQ microspheres. (water/MTMS ratio: 5:1, $\mathrm{pH}$ value of condensation reaction: 7.6 , temperature: $20^{\circ} \mathrm{C}$ ).

\begin{tabular}{ccccc}
\hline Sample & $\begin{array}{c}\text { Concentration } \\
(\mathrm{mmol} / \mathrm{L})\end{array}$ & $\begin{array}{c}\text { Average diameter } \\
(\mathrm{nm})\end{array}$ & $\begin{array}{c}\text { Standard deviation } \\
(\mathrm{nm})\end{array}$ & $\begin{array}{c}\text { Yield } \\
(\%)\end{array}$ \\
\hline PMSQ-C0 & 0 & 6115 & 472 & 89.0 \\
PMSQ-C1 & 0.5 & 1073 & 194 & 69.2 \\
PMSQ-C2 & 1.0 & 607 & 87 & 64.0 \\
PMSQ-C3 & 2.0 & 384 & 43 & 59.8 \\
PMSQ-C4 & 3.0 & 60 & 7 & 70.0 \\
PMSQ-C5 & 5.0 & 37 & 3 & 89.4 \\
\hline
\end{tabular}

Fig. 1 shows that the prepared microspheres have a greatly smooth and spherical appearance in photographic images, and no trace of aggregation of the PMSQ microspheres is observed during the preparation process.
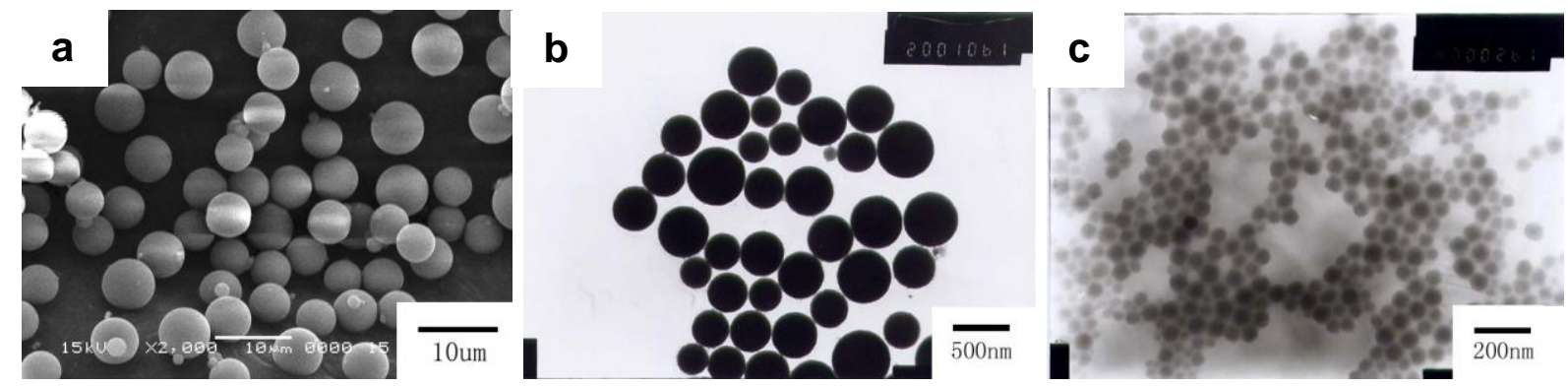

Fig. 1. photographs of the PMSQ microspheres with various concentrations of HTAC: (a) 0 , (b) $2 \mathrm{mmol} / \mathrm{L}$, (c) $3 \mathrm{mmol} / \mathrm{L}$.

\section{Effect of water/MTMS ratio on the size and morphology of PMSQ microspheres}

Table 2 and Fig. 2 show the effect of water/MTMS ratio on the microsphere size and standard deviation in a separate set of experiments. When the water/MTMS ratio ranges from 5:1 to 17:1, the PMSQ microspheres with an average diameter of 31$384 \mathrm{~nm}$ are obtained. Moreover, the alkalescence of reaction medium and the amount of micelles in the solution are ensured at a given base and HTAC concentration. The concentration of alkylsilanol in the solution accordingly falls down with the increasing of water/MTMS ratio.

The amount of alkylsilanol each micelle could gain correspondingly decreases. In that case, so the smaller microspheres are formed in the experiments at higher water/MTMS ratio. Furthermore, the yield of PMSQ microspheres (by filtration using 
membrane filter of $3 \mu \mathrm{m}$ ) is more than $70 \%$ by the two-step sol-gel method and it increases with the increasing of water/MTMS ratio.

Tab. 2. Effect of $W / O$ ratio on the size and yield of $P M S Q$ microspheres. $(\mathrm{pH}$ value of condensation reaction: $7.6, \mathrm{C}_{\mathrm{HTAC}}: 2 \mathrm{mmol} / \mathrm{L}$, temperature: $20^{\circ} \mathrm{C}$ ).

\begin{tabular}{ccccc}
\hline Sample & $\begin{array}{c}\text { Water/MTMS } \\
(\mathrm{V}: \mathrm{V})\end{array}$ & $\begin{array}{c}\text { Average diameter } \\
(\mathrm{nm})\end{array}$ & $\begin{array}{c}\text { Standard deviation } \\
(\mathrm{nm})\end{array}$ & $\begin{array}{c}\text { Yield } \\
(\%)\end{array}$ \\
\hline PMSQ-R1 & $5: 1$ & 384 & 43 & 73.3 \\
PMSQ-R2 & $9: 1$ & 215 & 22 & 72.1 \\
PMSQ-R3 & $11: 1$ & 126 & 11 & 74.5 \\
PMSQ-R4 & $13: 1$ & 74 & 8 & 85.7 \\
PMSQ-R5 & $17: 1$ & 31 & 4 & 92.1 \\
\hline
\end{tabular}

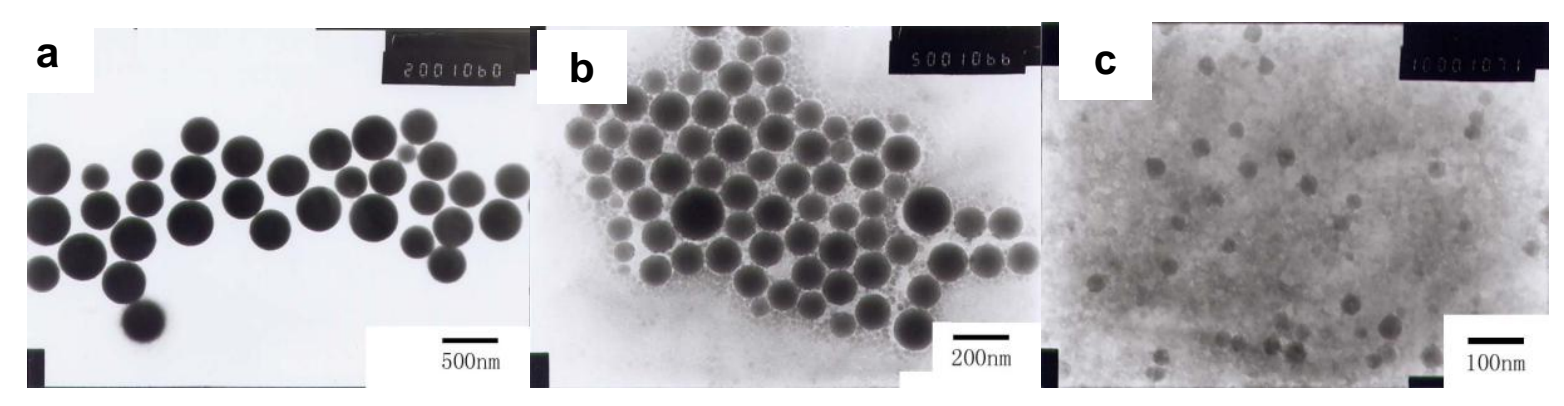

Fig. 2. Micrographs of PMSQ microspheres with different W/O ratio: (a) 5:1, (b) 11:1, (c) $17: 1$.

\section{Effect of $\mathrm{pH}$ value on the average diameter of PMSQ microspheres}

It is well known that the function of the ammonia solution is to promote the nucleation and growth of the PMSQ microspheres in the condensation reaction as a catalyst. The basic condition can provided fast nucleation and growth of the microspheres.

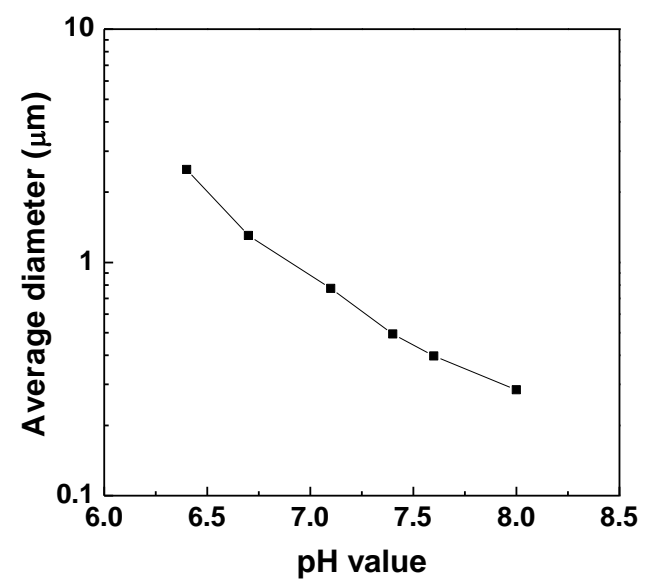

Fig. 3. Effect of $\mathrm{pH}$ value of condensation reaction on the microsphere's average diameter. (water/MTMS ratio: 5:1, $\mathrm{C}_{\mathrm{HTAC}}: 2 \mathrm{mmol} / \mathrm{L}$, temperature: $20^{\circ} \mathrm{C}$ ) 
Fig. 3 shows the effect of $\mathrm{pH}$ value (the basic concentration) on the size of PMSQ microspheres.

Just like those synthesized by suspension polymerization, $\mathrm{pH}$ value of condensation reaction has done a great effect on the size of PMSQ microspheres obtained by the two-step sol-gel method. The PMSQ microspheres with an average diameter of 0.28 $2.5 \mu \mathrm{m}$ can be prepared when the $\mathrm{pH}$ value is between 6.4 and 8.0 , and the larger PMSQ microspheres are formed at smaller $\mathrm{pH}$ value. Therefore, with the $\mathrm{pH}$ value increasing, the microspheres become smaller.

\section{Effect of temperature on the size and yield of PMSQ microspheres}

The influence of the temperature of the condensation reaction in the case of HTAC on the size and yield of PMSQ microspheres was also investigated. The results obtained are compared in Table3 when condensation reaction was accomplished at 0,20 and $40^{\circ} \mathrm{C}$, respectively.

Tab. 3. Effect of temperature on the size and yield of $P M S Q$ microspheres. (water/MTMS ratio: 5:1, $\mathrm{pH}$ value of condensation reaction: $7.6, \mathrm{C}_{\mathrm{HTAC}}: 2 \mathrm{mmol} / \mathrm{L}$ ).

\begin{tabular}{lccccc}
\hline Sample & $\begin{array}{c}\text { Temperature } \\
\left({ }^{\circ} \mathrm{C}\right)\end{array}$ & $\begin{array}{c}\text { Average } \\
\text { diameter }(\mathrm{nm})\end{array}$ & $\begin{array}{c}\text { Standard } \\
\text { deviation }(\mathrm{nm})\end{array}$ & $\begin{array}{c}\text { Coefficient of } \\
\text { variation }(\%)\end{array}$ & $\begin{array}{c}\text { Yield } \\
(\%)\end{array}$ \\
\hline PMSQ-T1 & 0 & 205 & 33 & 16.1 & 72.1 \\
PMSQ-T2 & 20 & 384 & 43 & 11.2 & 73.3 \\
PMSQ-T3 & 40 & 448 & 133 & 30.0 & 76.7 \\
\hline
\end{tabular}

The results indicate that the temperature of condensation reaction has great significance on the size of PMSQ microspheres obtained from the two-step sol-gel method. The average diameter and standard deviation of PMSQ microspheres both increase with the raise of the reaction temperature. However, the coefficient of variation has another rule. The coefficient of variation is larger than that in middle temperature $\left(20^{\circ} \mathrm{C}\right)$ when the temperature arranges in lower or higher area, so the condensation process carried out at the temperature of $20{ }^{\circ} \mathrm{C}$ is likely a favourable choice. Meanwhile, when the temperature of condensation reaction is rising, the yield of PMSQ microspheres increases slightly. The trend can be explained as the higher reactivity of the reaction components at higher temperatures.

\section{Thermal stability}

TGA curves in different atmospheres of PMSQ-C3 microspheres are shown in Fig.4 and the characteristic mass loss data are listed in Table 4. It can be seen that the temperature of $1 \mathrm{wt} \%$ mass loss for $\mathrm{PMSQ}$ in nitrogen is $234^{\circ} \mathrm{C}$ and $245^{\circ} \mathrm{C}$ for the microspheres in air, which indicates that the mass loss onset temperatures of PMSQ thermal degradation little affect by the atmosphere.

The mass loss prior to $190{ }^{\circ} \mathrm{C}$ in air atmosphere is $0.6 \mathrm{wt} \%$, this being mainly associated with volatilization of low-molecular-weight products. A mass loss of $1.9 \mathrm{wt} \%$ is observed at $190-440{ }^{\circ} \mathrm{C}$ in air due to condensation reaction of residual silanols and methoxy groups, followed by a large mass loss of $7.1 \mathrm{wt} \%$ from $440{ }^{\circ} \mathrm{C}$ to $480{ }^{\circ} \mathrm{C}$ assigned to decomposition of methyl groups. The microspheres in nitrogen atmosphere exhibit a mass loss of $3.1 \mathrm{wt} \%$ at a temperature below $470{ }^{\circ} \mathrm{C}$ attributable to residuals silanols and methoxy groups and low-molecular-weight products. A rapid 
mass loss of $8.2 \mathrm{wt} \%$ occurs from 470 to $710^{\circ} \mathrm{C}$, and a weight loss of $8.5 \mathrm{wt} \%$ over the range of $710-900^{\circ} \mathrm{C}$ is found. Total mass loss in nitrogen atmosphere is $19.8 \mathrm{wt} \%$, which is increased by $6.6 \mathrm{wt} \%$ than that in air atmosphere.

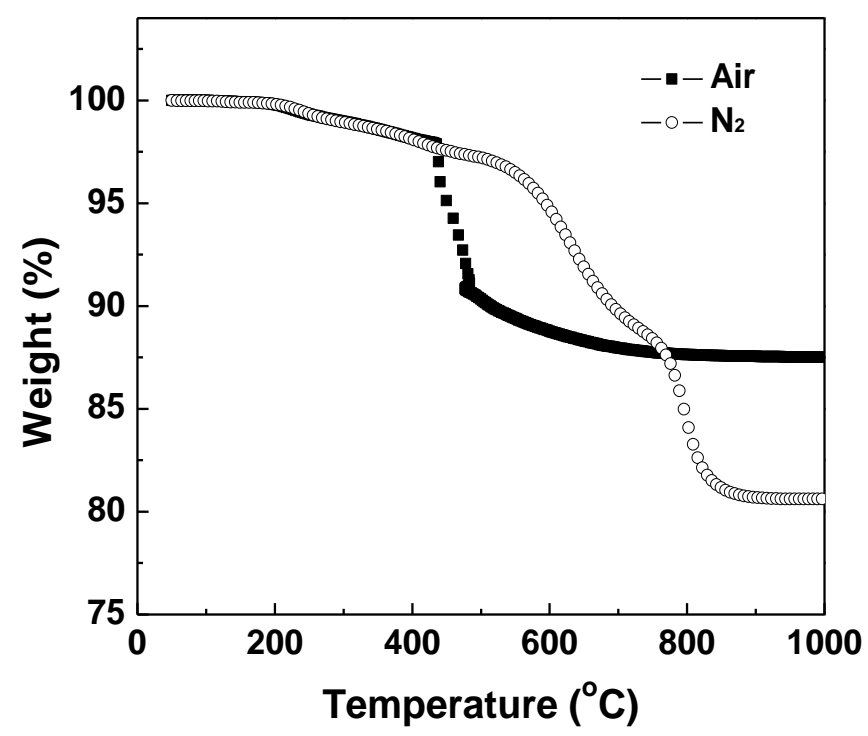

Fig. 4. TGA curves of $P M S Q$ microspheres in different atmosphere.

However, what more interests us is that the mass loss in inert (nitrogen) atmosphere is more than that in air atmosphere, which is different from the literature [33]. It is self-evident that $\mathrm{Si}-\mathrm{CH}_{3}$ groups exist in the PMSQ microspheres. Indeed, it also be confirmed that some of $\mathrm{Si}-\mathrm{OCH}_{3}$ and $\mathrm{Si}-\mathrm{OH}$ groups still remain in the microspheres. When the temperature increases, $\mathrm{Si}-\mathrm{CH}_{3}$ bond is broken earlier than $\mathrm{Si}-\mathrm{OH}$ and $\mathrm{Si}$ $\mathrm{OCH}_{3}$ bonds. Due to the oxidation reaction in air atmosphere, $\mathrm{Si}-\mathrm{CH}_{3}$ and $\mathrm{Si}-\mathrm{OH}$ bonds both convert into Si-O bond, while in the inert (nitrogen) atmosphere only bond-broken mode occurs. Thus the interesting phenomenon in weight loss of the PMSQ microspheres takes place.

Tab. 4. Resulting date of TGA in different atmosphere.

\begin{tabular}{|c|c|c|c|c|c|c|}
\hline \multirow{2}{*}{ Atmosphere } & \multicolumn{4}{|c|}{ Temperature $\left({ }^{\circ} \mathrm{C}\right)$} & \multirow{2}{*}{$\begin{array}{c}\text { Peak rate } \\
\text { (\%/min) }\end{array}$} & \multirow{2}{*}{$\begin{array}{l}\text { Residues } \\
\text { (wt\%) }\end{array}$} \\
\hline & $T_{1 \%}$ & $T_{5 \%}$ & $T_{10 \%}$ & $T_{\max }$ & & \\
\hline Air & 245 & 470 & 503 & 484 & - & 87.1 \\
\hline $\mathrm{N}_{2}$ & 234 & 577 & 673 & 790 & 14.5 & 80.2 \\
\hline
\end{tabular}

\section{$X$-ray diffraction}

Since Brown [34] first reported the synthesis and stereostructure of the ladderlike polyphenylsilsesquioxane (PPSQ), its unique double-chain structure and properties have interested many polymer chemists. Contrary to polyphenylsilsesquioxane, there is little literature focused on the structure of polymethylsilsesquioxane. Polymethylsilsesquioxanes are simply described to have ladder structures (I) based on their IR spectra [35]. Zhang [36] reported that the XRD analysis of one PMSQ sample presented broad reflections assigned to the plane-to-plane distance at $8.7 \AA$

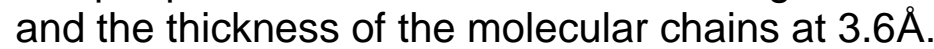




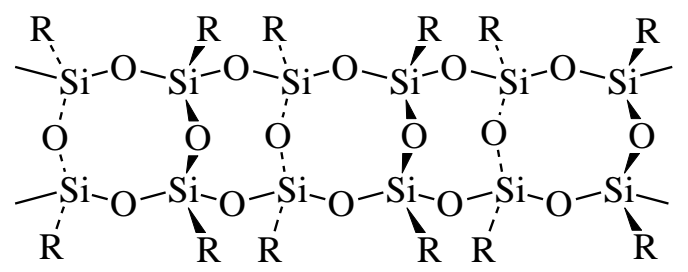

\section{(I) Ladder structure}

Fig. 5. XRD pattern of PMSQ-a and -b microspheres.

In the Fig. 5, the sample of PMSQ-a is prepared in no presence of surfactant solution, but another sample-b (PMSQ-C3) is contrarily from the reaction system containing surfactant. It can be seen that the samples are both exhibited ladder structure, because of the two peaks in X-ray diffraction pattern of samples. The peak1 represents the plane-to-plane distance $d_{1}(\AA)$, which corresponds with the chain-tochain distance. The peak-2 represents the thickness, $d_{2}(\AA)$, of molecular chains. The more regular the structure, the larger d1 of the molecule is. From the Table 5, it can be obtained that the two samples ( $a$ and b) exhibit almost the same peaks in $3-50^{\circ}$. So the surfactant added to the reaction solution cannot affect the structure of PMSQ, which still be a ladder structure.

Tab. 5. The peak date of different samples in X-ray diffraction.

\begin{tabular}{ccccc}
\hline \multirow{2}{*}{ Sample } & \multicolumn{2}{c}{ Peak 1 } & \multicolumn{2}{c}{ Peak 2 } \\
\cline { 2 - 5 } & 2-Theta & $\mathrm{d}(\AA)$ & 2-Theta & $\mathrm{d}(\AA)$ \\
\hline $\mathrm{a}$ & 10.301 & 8.5808 & 22.377 & 3.9698 \\
$\mathrm{~b}$ & 10.220 & 8.6485 & 22.621 & 3.9274 \\
\hline
\end{tabular}

\section{FT-IR spectra}

The FT-IR spectrum of PMSQ-b is shown in Fig.6 and the bonds characteristic of the silicone network is found: $\mathrm{Si}-\mathrm{O}-\mathrm{Si}$ stretching vibration at $783 \mathrm{~cm}^{-1}$ and $\mathrm{Si}-\mathrm{O}-\mathrm{Si}$ asymmetric vibration around $1000-1200 \mathrm{~cm}^{-1}$. The presence of $\mathrm{Si}-\mathrm{CH}_{3}$ is proven at $1273 \mathrm{~cm}^{-1}$ and an asymmetric stretching vibration of $-\mathrm{CH}_{3}$ emerges at $2972 \mathrm{~cm}^{-1}$. Absorption at 1036 and $1126 \mathrm{~cm}^{-1}$ is due to the stretching of $\mathrm{Si}-\mathrm{O}-\mathrm{Si}$, which also can be used as an evidence of ladder structure. A slightly broad peak around $3500 \mathrm{~cm}^{-1}$ could be attributed both to the adsorbed water and to the hydrogen-bonded $\mathrm{Si}-\mathrm{OH}$ group. 


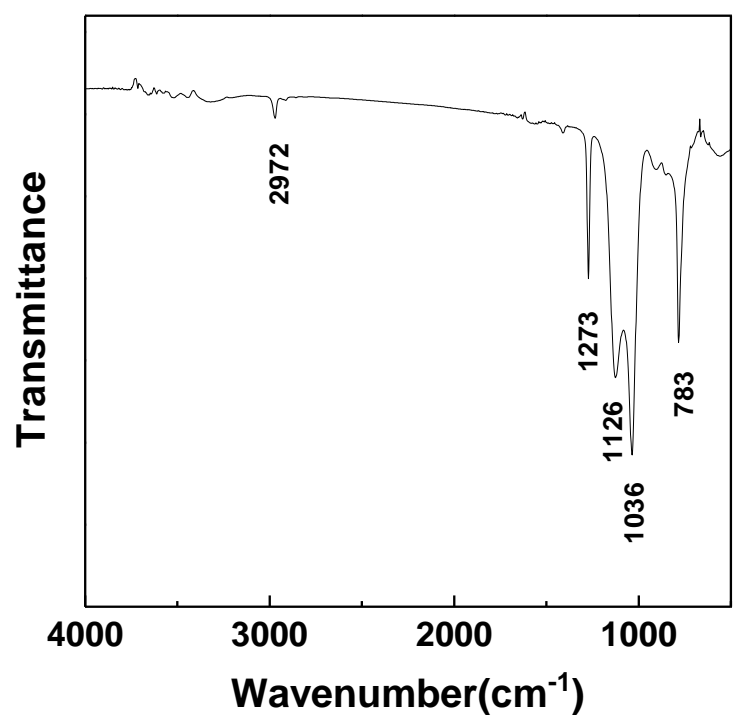

Fig. 6. FT-IR spectra of the PMSQ-b microspheres.

\section{Conclusions}

PMSQ microspheres with an average diameter of about $30 \mathrm{~nm}$ to $6 \mu \mathrm{m}$ can be prepared from MTMS by a two-step sol-gel method in the case of HTAC. The HTAC concentration is decisive in determining the microsphere size. The higher HTAC concentrations favor a decrease in the average diameter and standard deviation of the PMSQ microspheres. An increase of water/MTMS ratio and $\mathrm{pH}$ value of condensation reaction also both cause the decreasing of the microspheres' average diameter. The condensation reaction carried in middling temperature around $20{ }^{\circ} \mathrm{C}$ is favorable for the synthesis of the PMSQ microspheres with a relative small coefficient of variation. In addition, the higher water/MTMS ratio and temperature are both more efficient with respect to increasing the yield of the PMSQ microspheres. The thermal stability of PMSQ microspheres was also investigated, and it exhibits an excellent thermal stability and has only $3 \mathrm{wt} \%$ weight loss arrived at $450{ }^{\circ} \mathrm{C}$, no matter in air or nitrogen atmosphere. Furthermore, the surfactant added to the reaction solution cannot affect the molecule alignment of prepared PMSQ structure, which is still a ladder structure.

\section{Experimental part}

\section{Materials}

Methyltrimethoxysilane (MTMS; Danyang Organosilicon Material Industrial Corporation), hydrochloric acid ( $\mathrm{HCl}$; Shanghai Lingfeng Chemical) and ammonium hydroxide ( $\mathrm{NH} 4 \mathrm{OH}$; Yixin Sunan Chemical Material Plant) were all reagent grades and used as received. Hexadecyl trimethyl ammonium chloride (HTAC; Shanghai Jingwei Chemical) was commercial grades and used without further purification.

\section{Preparation}

The synthesis of the PMSQ microspheres by the two-step sol-gel reaction using MTMS as the monomer in the presence of HTAC was accomplished according to the following procedure. The reaction was carried out in a $250 \mathrm{ml}$ four-neck glass reactor equipped with a mechanical stirrer and a refluxing condenser at atmospheric 
pressure. The monomer (MTMS) and deionized water were introduced into the reactor, controlling the $\mathrm{pH}$ value of solution at 4.0 by hydrochloric acid. After the mixture was slowly stirred at $20{ }^{\circ} \mathrm{C}$ for $5 \mathrm{~h}$, a prescribed amount of HTAC was added dropwise into the reactor. Then, an ammonia solution was also added quickly into the mixture to control the $\mathrm{pH}$ value of solution to the desired value. The condensation reaction was continued for $4 \mathrm{~h}$ and the latex was generated. The above latex was coagulated in a $3 \mathrm{wt} \%$ aqueous calcium chloride solution, via slow addition of 1 part of latex to 1.5 part of aqueous calcium chloride solution. The resulting polymer solids were filtrated and the filter was repeatedly washed with deionized water. This was followed by drying for $12 \mathrm{~h}$ under $110^{\circ} \mathrm{C}$ and the PMSQ microspheres were attained.

The standard condition of preparation of PMSQ microspheres as following: water/MTMS ratio $(\mathrm{V}: \mathrm{V}): 5: 1, \mathrm{pH}$ value of condensation reaction: $7.6, \mathrm{C}_{\mathrm{HTAC}}: 2 \mathrm{mmol} / \mathrm{L}$, temperature: $20^{\circ} \mathrm{C}$.

\section{Characterization}

The morphology of PMSQ microspheres was observed with a transmission electron microscopy (TEM) (JEM-100CX, JEOL) and a scanning electron microscopy (SEM) (JSM-6360LV, JEOL). The number average diameter and standard deviation of microspheres size were measured by the following procedure: 50 microspheres were arbitrarily selected by the photographic image. The average diameter of the selected microspheres was measured from the photographs and the standard deviation of the microsphere size was calculated from the diameters of each microsphere.

The FT-IR spectra of PMSQ microspheres were recorded using an IR spectrometer (Equinox-55, Bruker). The spectra were obtained at a resolution of $2 \mathrm{~cm}^{-1}$ with 20 scans and the sample was examined as $\mathrm{KBr}$ disk. The thermal stability of $\mathrm{PMSQ}$ microspheres was performed on a thermal analyzer (Q600, TA). Around $10 \mathrm{mg}$ sample was heated from $50{ }^{\circ} \mathrm{C}$ up to $1000{ }^{\circ} \mathrm{C}$ at a heating rate of $20{ }^{\circ} \mathrm{C} / \mathrm{min}$, and the velocity of gas flow was kept in $100 \mathrm{ml} / \mathrm{min}$. The X-ray diffraction analysis of sample was recorded on diffractometer (D/max-2500, Rigaku).

\section{References}

[1] Botti, S.; Celeste, A.; Coppola, R. Appl. Organomet. Chem. 1998, 12, 361.

[2] Noda, I.; Kamoto, T.; Sasaki, Y.; Yamamda, M. Chem. Soc. 1999, 11, 3693.

[3] Brunet, F. J. Non-Cryst. Solids. 1998, 231, 58.

[4] Dubitsky, Y.; Zaopo, A.; Zannoni, G.; Zetta, L. Mater. Chem. Phys. 2000, 64, 45.

[5] Jones, S. M. J. Non-Cryst. Solids. 2001, 291, 206.

[6] Zhang, Z. Y.; Sakka, S. J. Sol-Gel. Sci. Technol. 1999, 16, 209.

[7] Tagaya, A.; Koike, Y. Macromol. Symposia. 2000, 154, 73.

[8] Haga, Y. O.; Utsunomiya, T. F.; Shimodate, K. O. US5352747, 1994.

[9] Hah, H. J.; Koo, S. M. J. Sol-Gel. Sci. Technol. 2004, 31, 117.

[10] Perry, R. J.; Adams, M. E. Am. Chem. Soc. 2000, 36, 533.

[11] Oikawa, N. J. Sol-Gel. Sci. Technol. 2000, 19, 729.

[12] Arkhireeva, A.; Hay, J. N. J. Mater. Chem. 2003, 13, 3122.

[13] Liu, R. L.; Xu, Y.; Wu, D.; Sun, Y. H.; Gao, H. C.; Yuan, H. Z.; Deng, F. J. NonCryst. Solids. 2004, 343, 61.

[14] Koji, S. JP2002322282, 2002.

[15] Yoshinori, I. JP2001294670, 2001. 
[16] Dong, H. J.; Lee, M.; Thomas, R. D.; Zhang, Z. P.; Reidy, R. F.; Mueller, D. W. J. Sol-Gel. Sci. Technol. 2003, 19, 729.

[17] Van, B. A.; Vrij, A. J. Colloid Interf. Sci. 1993, 156, 1.

[18] Baumann, F.; Schmidt, M.; Deubzer, B.; Geck, M.; Dauth, J. Macromolecules. 1994, 27, 6102.

[19] Smith, K. A. Macromolecules. 1987, 20, 2514.

[20] Prabakar, S.; Assink, R. A. J. Non-Cryst. Solids. 1997, 211, 39.

[21] Kazuki, N. Jpn. J. Polym. Sci. Technol. 2000, 57, 396.

[22] Vogel, R.; Surawski, P. P.; Littleton, B. N.; Miller, C. R.; Lawrie, G. A.; Battersby, B. J.; Trau, M. J. Colloid Interf. Sci. 2007, 310, 144.

[23] Lu, X.; Yin, Q. F.; Xin, Z.; Zhang Z. Q. Chem. Engine. Sci. 2010, 65, 6471.

[24] Miller, C. R,; Vogel, R.; Surawski, P. P. T.; Jack, K. S.; Corrie, S. R.; Trau, M. Langmuir. 2005, 21, 9733.

[25] Matsumoto, T.; Takayama, Y.; Wada, N.; Onada, H.; Kojima, K.; Yamada, H.; Wakabayashi, H. J. Mater. Chem. 2003, 13, 1764.

[26] Arriagada, F. J.; Asare, O. K. J. Colloid Interf. Sci. 1999, 211, 210.

[27] Noda, I.; Isikawa, M.; Yamawaki, M.; Sasaki, Y. Inorg. Chim. Acta. 1997, 263, 149.

[28] Noda, I.; Kamoto, T.; Yamada, M. Chem. Soc. 2000, 12, 1708.

[29] Li, Y. S.; Le, K. Spectrochim. Acta. Part A. 2004, 60, 927.

[30] Vainrub, A.; Devreux, F.; Boilot, J. P.; Chaput, F.; Sarkar, M. Mater. Sci. Eng. 1996, B37, 197.

[31] Matsumoto, T.; Takayama, Y.; Onoda, H.; Kojima, K.; Wada, N. J. Am. Ceram. Soc. 2005, 88, 3458.

[32] Jungmann, N.; Schmidt, M.; Maskos, M. Macromolecules. 2001, 34, 8347.

[33] Rao, A. V.; Kulkarni, M. M.; Amalnerkar, D. P.; Seth, T. Appl. Surf. Sci. 2003, 206, 262.

[34] Brown, J. F.; Vogt, L. H.; Prescott, P. I. J. Am. Chem. Soc. 1964, 86, 1120.

[35] Baney, R. H.; Itoh, M.; Sakakibara, A.; Suzukit, T. Chem. Rev. 1995, 95, 1409.

[36] Xie, Z. S.; He, Z. Q.; Dai, D. R.; Zhang, R. B. Chin. J. Polym. Sci. 1989, 7, 183. 